\title{
Posterior sagittal approach has a role in treatment of low cancer rectum
}

\author{
Tarek Gobran, MD; Emad M Salah, MD
}

Department of Surgery, Zagazig University, Egypt.

\begin{abstract}
Posterior sagittal approaches allow complete anatomic exposure of the perineum and lower pelvis. Moreover, they reduce the risk of damaging important structures because the incision is led in the midline.

Objective: To evaluate feasibility and efficacy of removal of a small malignant tumor in the lower rectum through a posterior sagittal approach.

Patients and methods: Between March 2007 to May 2010, twenty one patients (12 males and 9 females) mean age 52.3 years were submitted to posterior sagittal approach for resection of the tumor in the lower and middle rectum. Clincal examination and history, per-rectal examination and transrectal ultrasound: to all patients to evaluate the size of the tumor and depth of invasion.

Results: Straining during the act in 17 (81.6\%) patients, incomplete defecation in 11 (52.8\%) patients and bleeding in $12(57 \%)$ patients. Per-rectal examination: the mass was felt at the level from 6 to $7 \mathrm{~cm}$ with mean distance from the anal verge $6.4 \mathrm{~cm}$. There were no post operative complications in the form of anastomatic fistula, wound infection and anastomotic stenosis. There was no postoperative mortality. Continence function: excellent control of solid, liquid stool and flatus. 8 patients(38.4\%) had 7-10 bowel movements per day whereas the others had only 3 to 4 movements daily, subsequently the frequency of bowel movements became normal in all patients within 3 months with 1 to 3 bowel movements per day.

Conclusion: Posterior sagittal approach had good exposure of the rectum and facilitated the mobilization of the rectum and resection without traction prolapsed through the anus as occuring in intersphincteric resection and gave good space for perfect anastmosis.

Key words: Posterior sagittal approaches lower cancer rectum.
\end{abstract}

\section{Introduction:}

Rectal excision may be necessary for non malignant condition using a posterior sagittal approach. The technique allows excellent exposure of the rectum, meticulous haemostasis, minimal risk of pelvic nerve injury and accurate reconstruction of the pelvic floor without the need for drainage. ${ }^{1}$

Posterior sagittal approach represents a useful alternative to treat many pelvic conditions and therefore it must be apart of armamentarium of the colorectal surgeons. ${ }^{2}$

The posterior intersphincteric approach to treat lower malignant rectal lesion had many complications as incontinence and fecal fistula. ${ }^{3}$
The aim of this study was to report the technical feasibility and efficacy and to remove small malignant tumor in the lower third of the rectum through a posterior sagittal approach

\section{Patients and Methods:}

Between March 2007 to May 2010, twenty one patients (12 males and 9 females), age range from 48 to 61 years (mean age 52.3 year) were submitted to posterior sagittal approach for resection of the tumor in the lower third of the rectum.

Clinical examination and history: straining during the act, incomplete defecation and bleeding during the defecation. Per-rectal examination to feel the mass, its mobility and evaluate its distance from the anal verge. 
Transrectal ultrasound: to all patients to evaluate the size of the tumor and depth of invasion.

Computed tomography (CT): to the pelvis and abdomen to detect any pelvic lymph node or other organ affection.

Other pre-operative investigations as cardiological examination and liver and renal functions assessment.

\section{Selective criteria}

1-Tumor located in lower third rectum.

2-Pre-operativetransrectal ultrasound showing

the tumor not invading the rectal wall.

3-Pre-operative biopsy showing well to moderate differentiation.

4-The size of tumor from 3 to $5 \mathrm{~cm}$.

\section{Perioperative management}

The colon was prepared for 3 days preoperatively with saline enemas, oral manitol and oral metronidazol 500mg T.D.S. and claforan $1 \mathrm{gm} / 12$ hour. The patients were fed with a low residue diet.. Twelve hours before the surgery, the patients fasted, and also for the first 5 days after surgery, and intravenous fluid and claforan and metronidazole were given.

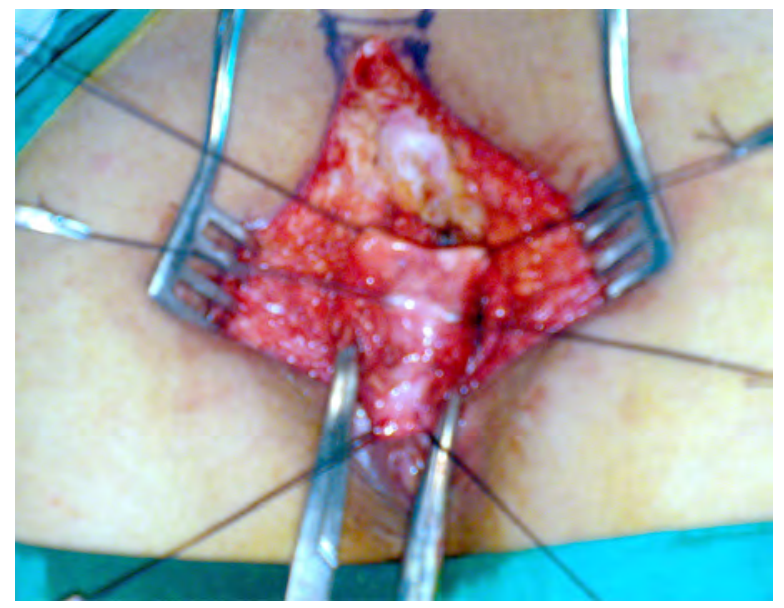

Figure (1): Mobilization of the rectum.

\section{Surgical procedure:}

The patient is positioned prone with the buttocks elevated on pillows and, after skin preparation and draping, a sagittal incision is made from coccyx to perineal body, circumcising the anus, which is gathered in a strong purse-string suture. The incision is deepened in a strictly sagittal plane, using fine needle-tip cautery which permits meticulous haemostasis. The external sphincter (parasagittal muscles) and levator ani can be readily identified and bisected precisely in the midline displaying the rectum. The rectum is mobilised by careful dissection on the rectal wall and self-retaining retractors are limited to superficial levels of the wound to minimize traction injury to pelvic nerves. The rectum can be mobilised with ease to the level of the peritoneal reflection where it is transected 6 $\mathrm{cm}$ above the tumor with total mesorectal excision and $3 \mathrm{~cm}$ distal to the tumor. After rectal resection the anastomosis was handsewn using interrupted sutures. No protective stoma was performed in all cases. The pelvic musculature is then closed accurately in layers and without drainage using polyglactin absorbable sutures. The skin is closed with fine interrupted sutures.

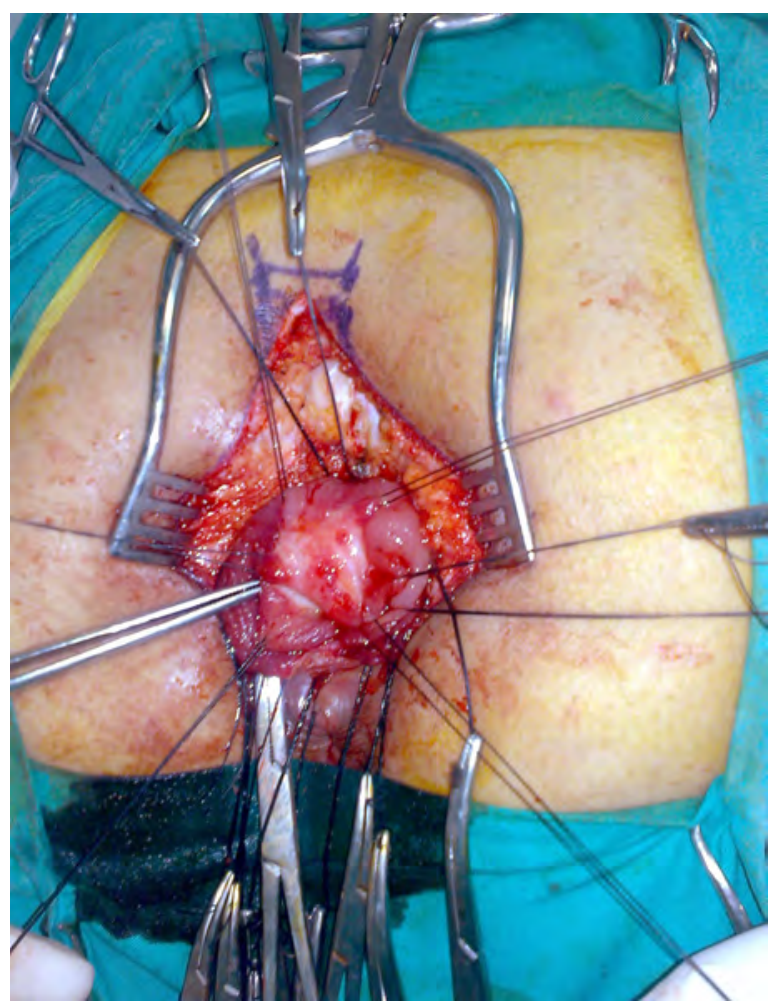

Figure (2): The malignant tumor in the lower third of the rectum. 


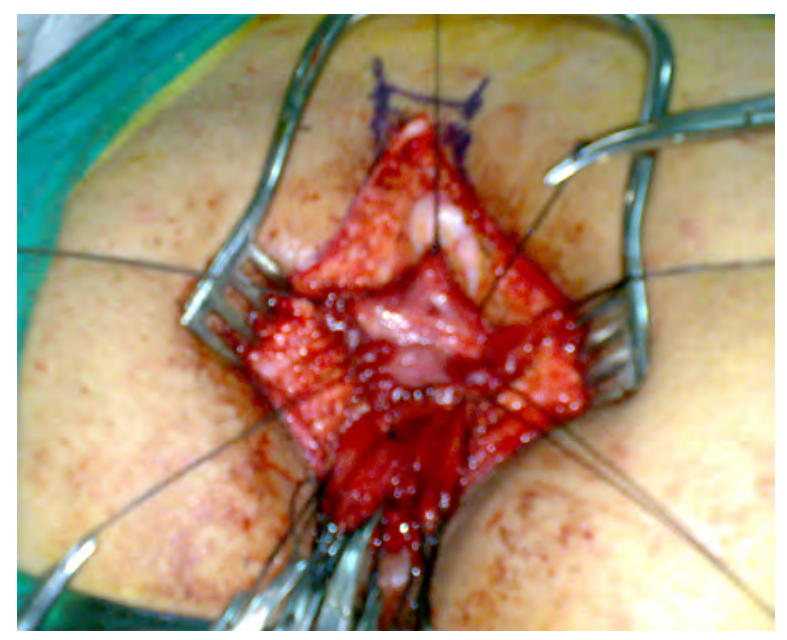

Figure (3): Resection of the tumor with proximal and distal safety margin.

\section{Results:}

The patients in this study included 12 males (57\%) and 9 females (43\%). Their age ranged from 48 to 61 years (mean age 52.3 years).

Clinical examination and history showed straining during the act in $17(81.6 \%)$ patients, incomplete defecation in $11(52.8 \%)$ patients and bleeding in $12(57 \%)$ patients. Per-rectal examination: the mass was felt 6 to $7 \mathrm{~cm}$ from the anal verge (mean $6.4 \mathrm{~cm}$ ).

The mean distance between the distal incision margin and the inferior border of the tumor was $1.8 \mathrm{~cm}$ (range $1.9 \mathrm{~cm}$ to $2.7 \mathrm{~cm}$ ). No evidence of residual tumor cells was present in the distal or proximal incision margins. According to TNM classification, 11(52.8\%)

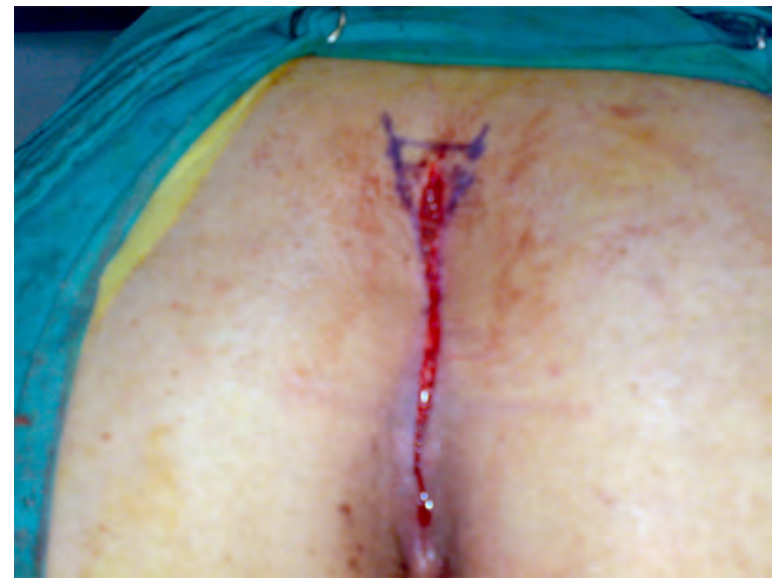

Figure (4B): Closed the subcutaneous space.

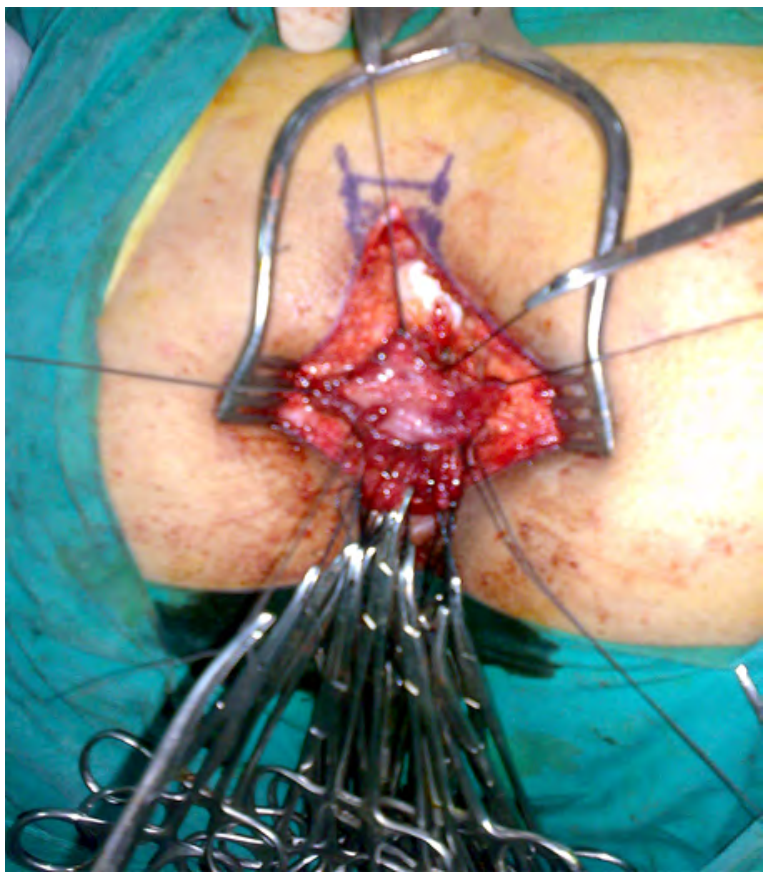

Figure (4A): Anastomosis of the proximal rectum to distal part.

patients were in stage I (T1), 7 (33.6) patients in stage II(T2) and 3 (14.4) patients in stage III (T3).

There were no post operative complications in the form of anastomotic fistula, wound infection and anastomotic stenosis. There was no postoperative mortality

Continence function tests were performed 3 and 6 months after surgery showed that all patients kept excellent control of solid, liquid stool and flatus. 8 patients $(38.4 \%)$ had $7-10$ bowel movements per day whereas the others had only 3 to 4 movements daily, subsequently the frequency of bowel movements became normal in all patients within 3 months with 1 to 3 bowel movements per day.

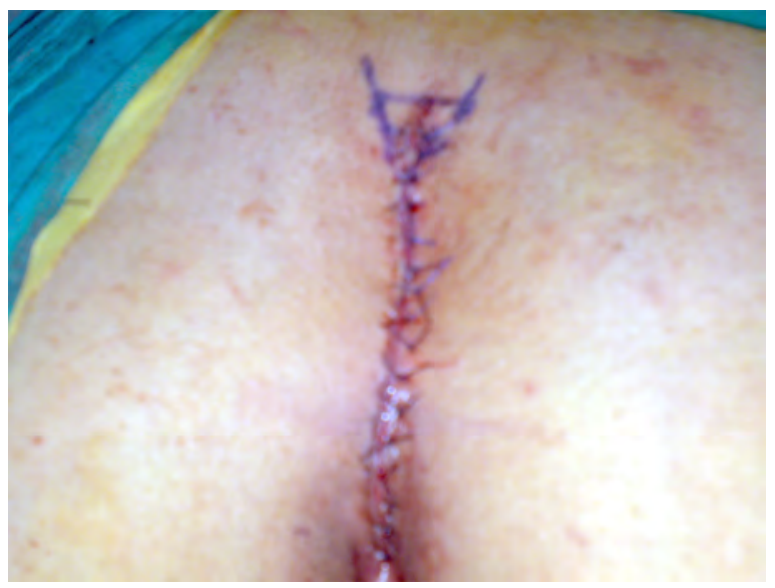

Figure (4C): Skin is closed with fine interrupted sutures. 
The parameters described by Pena were used for clinical evaluation of the bowel function.

1. Voluntary bowel movement is defined as the act of feeling the urge to use the toilet and holding the bowel movement until the patient reaches the bathroom.

2. Soiling is defined as the involuntary leaking of small amount of stool. This sign is quantified as grade 1 when the soiling occurs occasionally in minimal amounts, and the patient has no social problem. Grade 2 refers to soiling that occurs every day but does not cause any social problems. Grade 3 refers to soiling that is constant and represents a social problem to the patient.

3. Constipation is defined as the incapacity to empty the rectum spontaneously every day. It is quantified as grade 1 when the constipation is manageable by changes in diet, grade 2 when the patient requires laxatives, and grade 3 when the patient requires enemas.

All patients were followed for 10 to 50 months ( mean 33.8 months), patients must be follow up at regular interval every 3 months for per-rectal examination and 6 months for transrectal ultrasound to detect any local recurrence. 2 patients had local recurrence at 20 and 28 months after surgery and were treated by chemotherapy. 2 patients died from distal metastasis (41 and 45 months) and 3 patients had massive abdominal metastasis and lived for 25,30 and 31 months.

\section{Discussion:}

Posterior sagittal approaches allow complete anatomic exposure of the perineum and lower pelvis. Moreover, they reduce the risk of damaging important structures because the incision is led in the midline.$^{4}$

In our study, the mean distal incision margin $1.8 \mathrm{~cm}$ is sufficient for tumor free surgical resection line and can significantly reduce local recurrence. This is hand by hand with Dai et $\mathrm{al}^{4}$ who reported a mean distal incision margin of $1.6 \mathrm{~cm}$ in intersphincteric resection. But Chih et $\mathrm{al}^{5}$ were found that $1.2 \mathrm{~cm}$ is currently considered sufficient for low rectal cancer.
In this study there is no postoperative complication. But Daiet al ${ }^{3}$ and Chih et al ${ }^{5}$ found postoperative complications in the form of anastomatic fistula and wound infection in intersphincteric resection.

In this study all patients had excellent control of solid, liquid stool and flatus. But Dai et $\mathrm{al}^{3}$ found that $87 \%$ had excellent control in intersphincteric resection. But Barisic et al ${ }^{6}$ reported that $11.1 \%$ had complete incontinence and $13.3 \%$ had incomplete incontinence in intersphincteric resection.

As regard postoperative mortality, in this study there was no postoperative mortality. This agrees with Han et al ${ }^{7}$ and Barisic et al ${ }^{6}$ in intersphincteric resection. But Akasu et al ${ }^{8}$ and Akasu et $\mathrm{al}^{9}$ reported that the mortality in intersphincteric resection was $0.8 \%$ and $1 \%$ from sever leakage causing relaparotomy.

In this study no stoma was performed to cover the anastomosis. But Akasu et al, ${ }^{8}$ Barisic et $\mathrm{al}^{6}$ and Saito et al ${ }^{10}$ were found that a temporary diverting stoma may be beneficial to the improvement of the anal function in intersphincteric resection.

As regards local recurrence in this study, the mean local recurrence rate was $9.6 \%$. This is same as reported by Dai et $\mathrm{al}^{3}(8.7 \%)$ intersphincteric resection. But Akasu et al, ${ }^{8}$ Saito et a ${ }^{10}$ and Wang and Wei ${ }^{11}$ reported a lower rate of local recurrence in intersphincteric resection $(6 \%, 5.8 \%$ and $5 \%)$ respectively.

As regards the postoperative anastomotic stenosis, this was not reported in any case during the follow up. This is same as reported by Han et $\mathrm{al}^{7}$ and Akasu et $\mathrm{l}^{8}$ in intersphincteric resection. But Yamada et al ${ }^{12}$ reported that the anastomotic stenosis is a characteristic late complication.

It has been shown that 3 year disease free survival rate was $85.6 \%$ this is nearly same as Saito et $\mathrm{al}^{10}$ and Akasu et $\mathrm{al}^{9}$ in intersphincteric resection (91\% and $95 \%$ ) respectively. But in long follow up study for 5 year, free survival rate in intersphincteric resection was reported by Han et $\mathrm{al}^{7}$ and Saito et $\mathrm{al}^{10}$ (86\% and $\left.83.2 \%\right)$ respectively. 


\section{Conclusion:}

Posterior sagittal approach had good exposure of the rectum and facilitated the mobilization of the rectum and resection without traction prolapsed through the anus as occuring in intersphincteric resection and gave good space for perfect anastomosis.

\section{References:}

1- Stringer MS, Crabbe DC: Posterior sagittal proctectomy. Ann R Cll Sug Engl 1998; 80: 134-136.

2- Pean A: The posterior sagittal approach : Implications adult colorectal surgery. Dis Colon Rectum 1994; 37(1): 1-11.

3- Dai Y, Jiang JB, Bi DS, Jin ZT, Sun JZ, Hu SY: Preservation of the continence function after intersphincteric resection using a prolapsing technique in the patients with low rectal cancer and its clinical prognosis. Chin Med J Engl 2008; 121(20): 2016-2020.

4- Pini prato A, Martucciello G, Torre M, Jasonni V: Feasibility of posterior sagittal approach in patients without anorectal malformations. Ped Surg Inter 2004; 20(10): 762-767.

5- Chih-Chien, Chien-Yuh Yeh, Wen-Shih Huang and Jeng-Yi Wang: Clinical outcome of intersphincteric resection for ultra-low rectal cancer. World $J$ Gastroenterol 2006; 28: 12(4): 640-643.

6- Barisic G, Markovic V, Popovic M, Dimitrijevic I, Gavrilovic P, Krivokapic $\mathrm{Z}$ : Function after intersphincteric resection for low rectal cancer and its influence on quality of life. Colorectal Dis $2010 ; 20$.
7- Han JG, Wang ZJ, Wei GH, Xu HM, Yi BQ, Ma HC: Efficacy evaluation of anal intersphincteric resection with direct coloanal anastomosis for T1-2 ultra-low rectal cancer. Zhonghua Wei Chang Wai Ke Za Zhi 2010; 13(4): 256-259.

8- Akasu T, Takawa M, Yamamoto S, Yamaguchi T, Fujita S, Moriya Y: Risk factors for anastomotic leakage following intersphincteric resection for very low rectal adenocarcinoma. J Gastrointest Surg 2010; 14(1): 104-111.

9- Akasu T, Takawa M, Yamamoto S, Fujita $S$, Moriya $Y$ : Incidence and patterns of recurrence after intersphincteric resection for very low rectal adenocarcinoma. $\mathrm{J} \mathrm{Am}$ Coll Surg 2007; 205(5): 642-647.

10-Saito N, Moriya Y, Shirouzu K, Maeda K, Mochizuki H, Koda K, Hirai T, Sugito M, Ito M, Kobayashi A: Intersphincteric resection in patients with very low rectal cancer: A review of the Japanese experience. Dis Colon Rectum 2006; 49(10): 13-22.

11-Wang ZJ, Wei GH: Short-term results of sphincter-preserving operation with intersphincteric resection in low rectal cancer. Br J Surg 2007; 94(10): 1272-1277.

12-Yamada K, Ogata S, Saiki Y, Fukunaga M, Tsuji Y, Takano M: Long-term results of intersphincteric resection for low rectal cancer. Dis Colon Rectum 2009; 52(6): 1065-1071. 